\title{
VINEYARD WEATHER STATIONS IN MARLBOROUGH AND THEIR ROLE IN GRAPE DISEASE MANAGEMENT
}

\author{
R.H. AGNEW \\ HortResearch, Marlborough Wine Research Centre, P.O. Box 845, Blenheim, \\ New Zealand
}

Corresponding author: ragnew@hortresearch.co.nz

The grape industry in Marlborough has undergone rapid expansion with the area in production increasing from 2000 ha in 1995 to 10,000 ha in 2005. HortResearch in association with the Marlborough Wine Research Centre owns and operates a network of eight vineyard weather stations in order to monitor climatic variability and Botrytis cinerea infection conditions. Data are also collected from a further five privately owned stations. Weather and disease data are used to produce a weekly Vinefax service for the Marlborough grape industry. Temperature, growing degree days, rainfall and phenological data are summarised and compared with previous seasons. Levels of leaf and bunch powdery mildew (Uncinula necator) on monitored vineyards are summarised in order to allow growers to be on the alert for symptoms in their own vineyard. Botrytis cinerea infection periods are monitored using the Bacchus infection period model. Information is used by grapegrowers and winemakers as part of their decision making process. The network of 13 weather stations has allowed the different Marlborough sub-regions to be compared in order to gain an understanding of which sub-regions are at a higher risk of Botrytis cinerea infection. This information is being further developed within HortResearch to produce botrytis risk maps for Marlborough.

\section{FALCONS FOR GRAPES: A SOLUTION FOR BIRD DAMAGE?}

\author{
N.C. FOX ${ }^{1}$, V.P. SAXTON ${ }^{2}$, M.C.T. TROUGHT ${ }^{3}$ and J.D. HOLLAND ${ }^{4}$ \\ ${ }^{1}$ International Wildlife Consultants Ltd, Carmarthen SA335YL, United Kingdom \\ ${ }^{2}$ Centre for Viticulture and Oenology, PO Box 84, Lincoln University, New Zealand \\ ${ }^{3}$ Marlborough Wine Research Centre, 83 Budge Street, Blenheim, New Zealand \\ ${ }^{4}$ Massey University, Palmerston North, New Zealand \\ Corresponding author: saxtonv@lincoln.ac.nz
}

The New Zealand wine industry spends large amounts of money each year on protecting grapes from bird damage. In contrast to Europe, populations of exotic avian species that attack grapes are increasing. The 'Falcons for Grapes' project will use one wildlife problem - the conservation of the threatened New Zealand falcon (Falco novoseelandiae) - to mitigate another problem - bird damage to grapes. Generally, conservation is a luxury as it costs more money than it generates, but this project generates funding from commercial beneficiaries, namely the wine industry, to conserve the falcons. The objectives are to (1) establish a demographic monitoring programme for wild New Zealand falcons in the Marlborough Hills, (2) establish a new population of New Zealand falcons in the vineyards area of Marlborough and (3) develop a cost-effective method of significantly reducing bird damage to grapes. Young wild falcons will be encouraged to be almost self-sufficient in the vineyards by establishing predator-safe nesting sites in mussel barrels, encouraging the innate nest-imprinting of young falcons and providing a healthy and regular food supply. With $50 \%$ of bird control spent on human patrols and $30 \%$ on netting, considerable cost reductions are anticipated by having falcons patrolling vineyards. 